\title{
Leucine disposal rate for assessment of amino acid metabolism in maintenance hemodialysis patients
}

\author{
Gerald B. Denny ${ }^{1,3}$, Serpil M. Deger ${ }^{1,2,3}$, Guanhua Chen ${ }^{3,4}$, Aihua Bian ${ }^{3,4}$, Feng Sha ${ }^{1,3}$, Cindy Booker ${ }^{1,2,3}$,
} Jaclyn T. Kesler ${ }^{1,3}$, Sthuthi David ${ }^{5}$, Charles D. Ellis ${ }^{1,3}$ and T. Alp Ikizler ${ }^{1,2,3^{*}}$

\begin{abstract}
Background: Protein energy wasting (PEW) is common in patients undergoing maintenance hemodialysis (MHD) and closely associated with poor outcomes. Insulin resistance and associated alterations in amino acid metabolism are potential pathways leading to PEW. We hypothesized that the measurement of leucine disposal during a hyperinsulinemic- euglycemic-euaminoacidemic clamp (HEAC) procedure would accurately measure the sensitivity to insulin for its actions on concomitant carbohydrate and protein metabolism in MHD patients.

Methods: We examined 35 MHD patients and 17 control subjects with normal kidney function by hyperinsulinemic-euglycemic clamp (HEGC) followed by HEAC clamp procedure to obtain leucine disposal rate (LDR) along with isotope tracer methodology to assess whole body protein turnover.

Results: The glucose disposal rate (GDR) by HEGC was $5.1 \pm 2.1 \mathrm{mg} / \mathrm{kg} / \mathrm{min}$ for the MHD patients compared to $6.3 \pm 3.9 \mathrm{mg} / \mathrm{kg} / \mathrm{min}$ for the controls ( $p=0.38$ ). The LDR during HEAC was $0.09 \pm 0.03 \mathrm{mg} / \mathrm{kg} / \mathrm{min}$ for the MHD patients compared to $0.11 \pm 0.05 \mathrm{mg} / \mathrm{kg} / \mathrm{min}$ for the controls $(p=0.009)$. The LDR level was correlated with whole body protein synthesis $(r=0.25 ; p=0.08)$, with whole body protein breakdown $(r=-0.38 p=0.01)$ and net protein balance $(r=0.85 ; p<0.001)$ in the overall study population. Correlations remained significant in subgroup analysis. The GDR derived by HEGC and LDR correlated well in the controls $(r=0.79, p<0.001)$, but less so in the MHD patients $(r=0.58, p<0.001)$.
\end{abstract}

Conclusions: Leucine disposal rate reliably measures amino acid utilization in MHD patients and controls in response to high dose insulin.

Keywords: Leucine disposal rate, Insulin resistance, Maintenance hemodialysis, Protein energy wasting, Glucose disposal rate

\section{Background}

Protein energy wasting (PEW) is known to exist in a large number of patients with end stage renal disease (ESRD) and is associated with increased risk of infections, hospitalizations, and death [1-7]. We have previously shown that type 2 diabetes mellitus (DM), a known insulin resistant state, has been identified as an independent predictor of loss of lean body mass (LBM) in incident and prevalent

\footnotetext{
* Correspondence: Alp.|kizler@vanderbilt.edu

'Division of Nephrology, Vanderbilt University Medical Center, 1161 21St Ave.

South \& Garland, S-3223 MCN, Nashville, TN 37232-2372, USA

${ }^{2}$ CSRD\&D, Veterans Administration Tennessee Valley Healthcare System,

Nashville, TN, USA

Full list of author information is available at the end of the article
}

patients receiving maintenance hemodialysis (MHD) [8]. We have also demonstrated that insulin resistance measured by practical methods such as homeostatic model assessment (HOMA) is negatively associated with percent change with arterial plasma leucine concentrations in response to high dose insulin administration suggesting insulin mediated AA uptake into muscle or suppression of protein breakdown or both in MHD patients [9]. As the major anabolic hormone of the body responsible for not only carbohydrate metabolism, but also amino acid and 
fatty acid metabolism, it is conceivable that impaired insulin signaling could lead to PEW, an entity described by the loss of LBM [10].

An important aspect of the evaluation of insulin sensitivity in any physiologic or non-physiologic state is the precision of its estimate. While assessment of carbohydrate metabolism has been well studied in multiple settings, there are limited studies on assessment of insulin's effects on protein metabolism in vivo, especially in disease states with known metabolic defects such as advanced kidney disease. We have previously shown that in MHD patients, plasma amino acid concentrations decrease during the hyperinsulinemic-euglycemic clamp (HEGC) procedure in relation to the glucose disposal rate (GDR) [9]. While these data indicate a close relationship between carbohydrate and protein metabolism in response to a hyperinsulinemic state, there remains need for examination of amino acid metabolism during the absorptive state, where the anabolic effects of insulin are substantially different compared to the post-absorptive state.

In order to examine this issue further, we performed a hyperinsulinemic-euglycemic-euaminoacidemic (HEAC) clamp study with the primary aim of developing a disposal rate for precise assessment of amino acid metabolism. Since it is neither synthesized nor degraded in muscle and its utilization is mainly driven by insulin, we used leucine as the representative amino acid for these assessments. Based on our previous data, we also hypothesized that the sensitivity to insulin for protein metabolism would correlate with similar sensitivity for glucose metabolism in the MHD patients and controls without kidney disease.

\section{Methods}

\section{Study population}

A total of 52 subjects, 35 MHD patients from the Vanderbilt University Outpatient Dialysis Unit and 17 volunteers without kidney disease were recruited between November 2011 and December 2014. Primary inclusion criteria for MHD group was being on MHD therapy at least 6 months with well-functioning hemodialysis vascular access and, on a thrice-weekly MHD program receiving an adequate dose of dialysis (single pool Kt/V $>1.2$ ). Exclusion criteria included patients with active infectious or inflammatory disease (i.e., vascular access infections, active connective tissue disorder, active cancer, HIV, and liver disease) and patients hospitalized within the last month prior to the study. Patients receiving steroids ( $>5 \mathrm{mg} /$ day) and/or immunosuppressive agents and patients with Type $1 \mathrm{DM}$ and type $2 \mathrm{DM}$ who were using insulin or insulin-sensitizing medications were also excluded. The Institutional Review Board of Vanderbilt University approved the study protocol and written informed consent was obtained from all study patients.

\section{Study procedures}

\section{Hyperinsulinemic-euglycemic (HEGC) clamp protocol}

All studies were performed after an overnight 8-h fasting period at the General Clinical Research Center (GCRC) at Vanderbilt University Medical Center (VUMC). Clamp studies were performed on a non-dialysis day in order to eliminate the potential effects of the hemodialysis therapy.

On the morning of the clamp study, for the MHD patients, the dialysis shunt was accessed using 15-gauge fistula needles placed in opposite directions at least 4 fingerbreadths apart. The venous needle was used for the infusion of insulin and dextrose. Arterial blood samples were taken through the dialysis needle placed at the arterial side of the dialysis access. An IV was placed into the contralateral forearm vein (preferably in a retrograde fashion) to obtain samples of venous blood. For the control subjects, an IV was inserted into an antecubital vein for the infusion of all test substances. Second and third IVs were placed antegradely and retrogradely in the opposite arm for blood sampling. The antegrade IV was placed distal to the retrograde IV and the hand was kept in a heated box to achieve arterialization of the venous blood [11]. The remaining IV was used for venous sampling.

A schematic diagram of the metabolic study protocol is depicted in Fig. 1. After obtain blood and breath samples at time point 0 , bolus injection of $\mathrm{NaH}^{13} \mathrm{CO}_{3}$ $(0.12 \mathrm{mg} / \mathrm{kg}), \mathrm{L}-\left(1-{ }^{13} \mathrm{C}\right)$ Leucine $(7.2 \mu \mathrm{mol} / \mathrm{kg}), \mathrm{L}$-(ring$\left.{ }^{2} \mathrm{H}_{5}\right)$ Phenylalanine $(3.6 \mu \mathrm{mol} / \mathrm{kg})$, and $6,6-{ }^{2} \mathrm{H}_{2}$ Glucose $(3.6 \mathrm{mg} / \mathrm{kg})$ to prime the $\mathrm{CO}_{2}$, Leucine, Phenylalanine, and Glucose pools and a continuous infusion of labeled Leucine $(0.12 \mu \mathrm{mol} / \mathrm{kg} / \mathrm{min})$, Phenylalanine $(0.06 \mu \mathrm{mol} /$ $\mathrm{kg} / \mathrm{min})$ and Glucose $(0.06 \mathrm{mg} / \mathrm{kg} / \mathrm{min})$ started and continued throughout the remainder of the study. The initial $2 \mathrm{~h}$ were for tracer equilibration. During the equilibration period, forearm blood flow was estimated by using capacitance plethysmography (model 2560 with URI/CP software version 3.0; Moro Bay, CA, USA). Metabolic cart (Med Graphics CPX/D metabolic cart; software version 6.1. St. Paul, MN) was used to measure simultaneous energy expenditure and respiratory quotient.

After equilibration period, baseline blood and breath sampling obtained between T120 min and T150 min for every $15 \mathrm{~min}$. A primed infusion of crystalline insulin at the concentration of $2.0 \mathrm{mu} / \mathrm{kg} / \mathrm{min}$ was then started at time point $150 \mathrm{~min}$ and maintained throughout the study procedure to obtain constant hyperinsulinemia. The goal plasma insulin concentration was $100 \mu \mathrm{U} / \mathrm{mL}$. The insulin dose used was determined by the required dose during HEGC study in patients with ESRD to suppress hepatic gluconeogenesis and allow the measurement of peripheral insulin resistance [12]. Following initiation of insulin, target plasma glucose levels were $90 \pm 5 \mathrm{mg} / \mathrm{dL}$, achieved by adjustment of $20 \%$ dextrose 


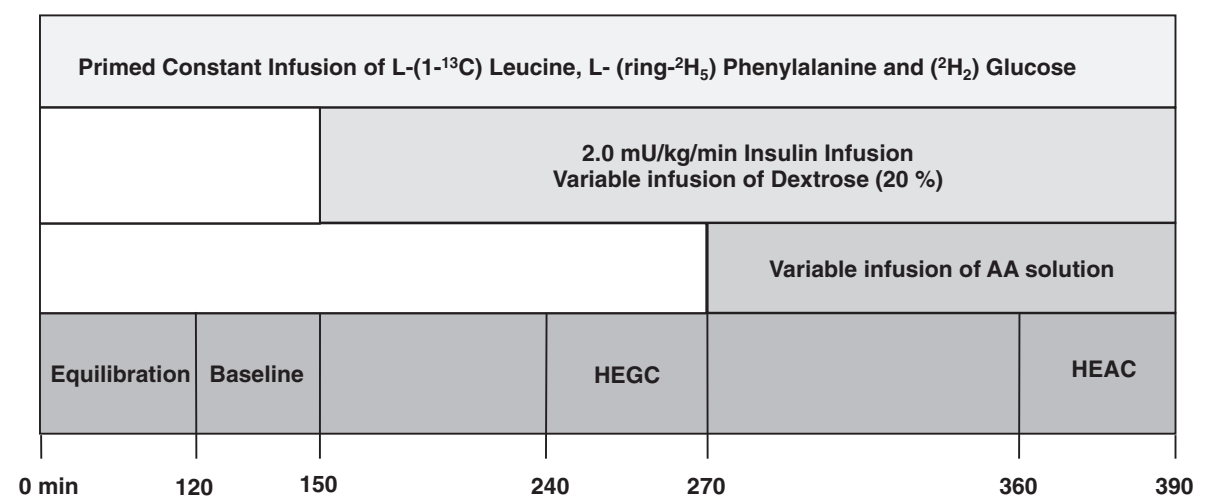

Fig. 1 HEGC and HEAC study protocol: AA; amino acid, HEGC; hyperinsulinemic-euglycemic clamp, HEAC; hyperinsulinemic-euglycemic-euaminoacidemic clamp

infusion. Constant monitoring of plasma glucose concentration was performed every $5 \mathrm{~min}$ and of leucine levels every $10 \mathrm{~min}$ using rapid bedside high-performance liquid chromatography (HPLC) methodology. Once steady state was reached and confirmed for $90 \mathrm{~min}$, GDR or the metabolizable glucose "M" value $(\mathrm{mg} / \mathrm{kg} / \mathrm{min}$ insulin mediated glucose disposal rate) was calculated from samples taken between time points 240 to $270 \mathrm{~min}$. This served as an index of in vivo insulin sensitivity. For reasons of comparison, the $\mathrm{M}$-value was normalized to body weight.

\section{Hyperinsulinemic-euglycemic-euaminoacidemic (HEAC) clamp protocol}

Once the HEGC was achieved, a continuous infusion of a balanced amino acid solution (Freeamine III $10 \%$, B. Braun Medical, Inc. Irvine, CA) (amino acid concentrations in Freeamine III: leucine, $910 \mathrm{mg}$; isoleucine, $690 \mathrm{mg}$; lysine, $730 \mathrm{mg}$; valine, $660 \mathrm{mg}$; phenylalanine, $560 \mathrm{mg}$; threonine, $400 \mathrm{mg}$; methionine, $530 \mathrm{mg}$; tryptophan $150 \mathrm{mg}$; alanine, $710 \mathrm{mg}$; arginine, $950 \mathrm{mg}$; glycine, $1400 \mathrm{mg}$; proline, $1120 \mathrm{mg}$; serine, $590 \mathrm{mg}$; histidine, $280 \mathrm{mg}$; cysteine, <16 mg; phosphoric acid NF, $120 \mathrm{mg}$; sodium bisulfite, $<100 \mathrm{mg}$ ) was administered at variable dose to achieve and maintain the leucine concentration similar to baseline state, which was calculated as the average level of time points $120 \mathrm{~min}, 135 \mathrm{~min}$, and $150 \mathrm{~min}$.

The formula for computing the periodically adjusted leucine infusion rate for every $10 \mathrm{~min}$ is

$$
\mathrm{R}(\mathrm{ml} / \mathrm{h})=\left(\mathrm{C}_{\mathrm{d}}-\mathrm{C}_{\mathrm{c}}\right) \times k \times 6
$$

The individual components of this formula are as follows: $\left(\mathrm{C}_{\mathrm{d}}-\mathrm{C}_{\mathrm{c}}\right)$ equals the leucine deficit or excess in $\mu \mathrm{M} / \mathrm{L}$ where $C_{d}$ is the desired plasma leucine concentration $(\mu \mathrm{M} / \mathrm{L})$. Multiplication by 6 converts the transfusion time from 10 min to one hour. $\mathrm{C}_{\mathrm{c}}$, is the actual plasma leucine concentration $(\mu \mathrm{M} / \mathrm{L})$ at any time point. Constant factor $k$ is derived from the formula of

$$
\left|\frac{B \times B W}{100} \times\left(\frac{1-H C T}{100}\right)\right| \times\left|\frac{9.1}{131.17} \times 1000\right|
$$

Total body blood volume is $8 \%$ of body weight. Multiplication by 1 minus hematocrit equals to the total plasma volume of total body. $9.1 \mathrm{mg}$ is the total leucine amount in $1 \mathrm{~mL}$ of Freeamine III solution. Division by 131.17 (molecular weight of leucine) and further multiplication by 1000 converts the leucine amount from milligram per liter to micromoles per liter.

When the steady state condition for leucine was achieved, the leucine infusion rate was assumed to be equal to the leucine incorporation rate into protein since endogenous leucine release from protein is assumed zero under steady state condition. Leucine disposal rate (LDR) was obtained by the leucine infusion rate (as in $\mathrm{mg} / \mathrm{min}$ ) during the final $30 \mathrm{~min}$ of the 390-min of study (steady state period for amino acids) and normalized by body weight $(\mathrm{kg})$.

\section{Body composition}

Within one week of each study, participants underwent dual-energy $\mathrm{x}$-ray absorptiometry (DEXA) offering a rapid, non-invasive three-compartment evaluation that quantifies fat mass, LBM, and bone mineral content with minimal radiation exposure. All DEXA measurements were completed on a non-dialysis day using a Lunar Prodigy iDEXA machine v.11.40.004 (software versions 2003 to 2011, General Electric, Madison, WI).

\section{Laboratory analysis}

All blood sampling was performed at the GCRC and analyzed at VUMC central laboratories. After blood draw was performed, samples were transported on ice and centrifuged at $3000 \mathrm{rpm}$ for $15 \mathrm{~min}$ before being 
kept frozen at $-80^{\circ}$ Celsius. Plasma fasting glucose concentrations were analyzed using the glucose oxidase method (Glucose analyzer 2; Beckman Coulter, Brea, CA). Biochemistry measurements were analyzed at the VUMC Pathology Laboratory. High sensitivity C-reactive protein (hs-CRP) concentrations were measured by high-sensitivity particle-enhanced turbidimetric UniCel DxI Immunoassay system (Beckman Coulter).

\section{Plasma amino acid measurements}

Plasma arterial amino acid concentrations were determined by reverse phase HPLC after derivatization with phenyliosthiocynate. Individual amino acids were also placed into groups for analysis purposes. These groups included branched chain amino acids $(B C A A=$ the sum of leucine, isoleucine, and valine), essential amino acids $(E A A=$ the sum arginine, histidine, isoleucine, leucine, lysine, methionine, phenylalanine, threonine, tryptophan, and valine), total amino acids (TAA = the sum of all individual amino acids), and nonessential amino acids $(\mathrm{NEAA}=$ the difference between TAA and EAA) [13].

\section{Whole body protein turnover}

The steady-state rates of total whole-body leucine $\mathrm{Ra}$ were calculated by dividing the $\left({ }^{13} \mathrm{C}\right)$ leucine infusion rate by the plasma $\left({ }^{13} \mathrm{C}\right) \mathrm{KIC}$ enrichment [14]. Steady state conditions for $\mathrm{KIC}$ and $\mathrm{CO} 2$ enrichments were achieved as evidenced by slopes within each phase not significantly different than zero. Breath ${ }^{13} \mathrm{CO}_{2}$ was determined by multiplying the total $\mathrm{CO}_{2}$ production rate by the breath ${ }^{13} \mathrm{CO}_{2}$ enrichment. The rate of whole body leucine oxidation was calculated by dividing breath ${ }^{13} \mathrm{CO}_{2}$ production by 0.8 (correction factor for the retention of ${ }^{13} \mathrm{CO}_{2}$ in the bicarbonate pool) [15] and by the plasma KIC enrichment. The leucine Rd, an estimate of whole-body protein synthesis, was determined indirectly by subtracting leucine oxidation from total leucine $\mathrm{Rd}$. Rates of whole-body protein breakdown, amino acid oxidation, and protein synthesis were calculated from the endogenous leucine $\mathrm{Ra}$, the leucine oxidation rate, and the non-oxidative leucine $\mathrm{Rd}$, respectively, assuming that $7.8 \%$ of whole-body protein is composed of leucine [16].

\section{Statistical analysis}

Descriptive statistics were expressed as mean \pm SD or median (IQR) for continuous variables and as frequencies and percentage for categorical variables. Univariate analysis was performed to compare differences between cases and controls using Pearson's $\chi^{2}$ test for categorical variables and Wilcoxon rank-sum test for continuous variables. Spearman rank correlations were used to estimate the correlation coefficient between LDR and GDR. Linear mixed-effects models with random intercepts were fitted separately to estimate the differences in leucine, phenylalanine, BCAA, EAA, NEAA, and TAA levels at baseline, HEGC, and HEAC between groups. Analyses were performed using R, version 3.2.3 (http:// www.r-project.org/). The $5 \%$ significance level (2-sided) was used.

\section{Results}

\section{Characteristics of study population}

Our study cohort comprised of 35 MHD and 17 control subjects. We screened $45 \mathrm{MHD}$ and 22 control subjects. Of 45 MHD patients, 3 patients excluded due to active infection, 3 due to prednisone usage, 3 due to hospitalizations within last one month and one patient due to diabetes mellitus requiring insulin therapy. Of 22 control subjects, 5 of them were excluded due to one subject had diabetes mellitus requiring insulin therapy and 4 refused consent. Clinical and laboratory characteristics of the study population are depicted in Table 1 . There were no significant differences for age, gender, and race between groups ( $p=0.25, p=0.77, p=0.23$, respectively). Maintenance hemodialysis patients were significantly more inflamed compared to control subjects [hs-CRP $4.0(1.8,10.6) \mathrm{mg} / \mathrm{L}$ for MHD vs $0.9(0.4,3.1) \mathrm{mg} / \mathrm{L}$ for control, $p<0.001]$. For MHD patients, median time on dialysis was $34(17,120)$ months. Hypertension, DM and glomerulonephritis were the primary disorders leading to $\operatorname{ESRD}$ (40,20 and $20 \%$, respectively), while one of the MHD patients had ESRD secondary to bilateral nephrectomy following diagnosis of renal cell carcinoma (3\%), one had due to polycystic kidney disease (3\%) and five due to unknown etiology (14\%).

\section{Plasma insulin and glucose concentrations}

Median baseline arterial plasma concentrations of insulin were $12(9,20) \mu \mathrm{U} / \mathrm{mL}$ for MHD patients and $12(5,14)$ $\mu \mathrm{U} / \mathrm{mL}$ for control subjects. Insulin infusion resulted in significant elevation of plasma insulin to median values of $100(48,153) \mu \mathrm{U} / \mathrm{mL}$ in the MHD group $(P<0.001$ versus baseline) and $133(114,145) \mu \mathrm{U} / \mathrm{mL}(p<0.001$ versus baseline) in the control group. The achieved arterial plasma concentration of insulin was similar in both groups $(p=0.20)$. There was no difference regarding plasma glucose concentrations between MHD subjects compared to controls $[98 \pm 17 \mathrm{mg} / \mathrm{dL}$ for MHD patients versus $105 \pm 23 \mathrm{mg} / \mathrm{dL}$ for control subjects $(p=0.11)]$. The glycemic goal of $90 \pm 5 \mathrm{mg} / \mathrm{dL}$ for both the HEGC and HEAC was reached in both groups during clamp periods.

\section{Plasma amino acid concentrations during the HEGC and HEAC study}

Although the MHD group tended to have higher baseline concentrations of leucine, this difference was not 
Table 1 Demographic and laboratory characteristics of study population $^{a}$

\begin{tabular}{|c|c|c|c|}
\hline & $\begin{array}{l}\text { Hemodialysis } \\
(n=35)\end{array}$ & $\begin{array}{l}\text { Control } \\
(n=17)\end{array}$ & $P$ \\
\hline $\mathrm{Age}_{1}^{\mathrm{b}} \mathrm{y}$ & $49 \pm 15$ & $45 \pm 11$ & 0.25 \\
\hline \multicolumn{4}{|l|}{ Race, $n(\%)$} \\
\hline African American & $28(80)$ & $11(65)$ & \\
\hline Caucasian & $7(20)$ & $6(35)$ & 0.23 \\
\hline Male sex, $n(\%)$ & $28(80)$ & $13(76)$ & 0.77 \\
\hline \multicolumn{4}{|l|}{ Primary Disorder of ESRD, $n(\%)$} \\
\hline Hypertension & $14(40)$ & & \\
\hline Diabetes Mellitus & $7(20)$ & & \\
\hline Glomerulonephritis & $7(20)$ & & \\
\hline RCC Bilateral Nephrectomy & $1(3)$ & - & NA \\
\hline Polycystic Kidney Disease & $1(3)$ & & \\
\hline Other & $5(14)$ & & \\
\hline Dialysis Vintage ${ }^{c}$ months & $34(17,120)$ & & NA \\
\hline \multicolumn{4}{|l|}{ Body Composition } \\
\hline $\mathrm{BMI}_{1}^{\mathrm{b}} \mathrm{kg} / \mathrm{m}^{2}$ & $29 \pm 6$ & $28 \pm 7$ & 0.34 \\
\hline Truncal Fat, ${ }^{\mathrm{b}} \%$ & $38 \pm 13$ & $33 \pm 12$ & 0.09 \\
\hline Fat Mass, ${ }^{c} \mathrm{~kg}$ & $30(23,37)$ & $24(15,31)$ & 0.21 \\
\hline Lean Mass, ${ }^{c} \mathrm{~kg}$ & $52(49,61)$ & $59(47,66)$ & 0.34 \\
\hline $\mathrm{BUN},{ }^{\mathrm{b}} \mathrm{mg} / \mathrm{dL}$ & $45 \pm 16$ & $13 \pm 3$ & $<0.001$ \\
\hline Creatinine, ${ }^{\mathrm{b}} \mathrm{mg} / \mathrm{dL}$ & $9.7 \pm 2.9$ & $0.9 \pm 0.1$ & $<0.001$ \\
\hline Albumin, ${ }^{b} \mathrm{~g} / \mathrm{dL}$ & $3.9 \pm 0.4$ & $4.0 \pm 0.2$ & 0.34 \\
\hline hs-CRP, ${ }^{c} \mathrm{mg} / \mathrm{L}$ & $4.0(1.8,10.6)$ & $0.9(0.4,3.1)$ & $<0.001$ \\
\hline Hematocrit, ${ }^{\mathrm{b}} \%$ & $37 \pm 5$ & $43 \pm 3$ & $<0.001$ \\
\hline Fasting Glucose, ${ }^{\mathrm{b}} \mathrm{mg} / \mathrm{dL}$ & $98 \pm 17$ & $105 \pm 23$ & 0.11 \\
\hline Baseline Insulin, ${ }^{c} \mu \mathrm{U} / \mathrm{mL}$ & $12.6(10.7,19.8)$ & $10.4(5.2,13.3)$ & 0.05 \\
\hline $\mathrm{HbA} 1 c_{1}^{\mathrm{b}} \%$ & $5.2 \pm 0.6$ & $5.3 \pm 0.5$ & 0.33 \\
\hline HOMA-IR, ${ }^{c}$ & $2.9(2.2,4.4)$ & $2.7(1.1,3.5)$ & 0.17 \\
\hline
\end{tabular}

${ }^{a} B U N$ blood urea nitrogen, $E S R D$ end stage renal disease, HbA1C hemoglobin A1c, hs-CRP high-sensitivity C-reactive protein, HOMA-IR homeostatic model assessment of insulin resistance, $R C C$ renal cell carcinoma

${ }^{\mathrm{b}}$ Mean $\pm \mathrm{SD}$

${ }^{\mathrm{C}}$ Median (IQR)

statistically significant when compared to control patients $[(104(83,124) \mu \mathrm{mol} / \mathrm{L}$ for MHD patients versus $92(89,107) \mu \mathrm{mol} / \mathrm{L}$ for control subjects $(p=0.26)]$. During HEGC period, insulin administration caused a consistent decline in plasma leucine concentrations in both groups. In MHD subjects, plasma leucine concentration decreased to $69(57,84) \mu \mathrm{mol} / \mathrm{L} \quad(p<0.001)$ whereas in control subjects, it decreased to $58(48,75)$ $\mu \mathrm{mol} / \mathrm{L}(p<0.001)$. During HEAC period, amino acid infusion led to an increase in plasma leucine concentration for both groups, which was sustained at baseline levels during steady state period $[105(87,127) \mu \mathrm{mol} / \mathrm{L}$ for MHD patients $(p=0.95)$ vs $92(83,106) \mu \mathrm{mol} / \mathrm{L}$ for control subjects $(p=0.73)$ ] (Fig. 2).
Although baseline plasma BCAA and NEAA concentrations were slightly higher and EAA and TAA concentrations were lower in control subjects compared to MHD patients, these differences were not statistically significant $(p=0.64$ for BCAA, $p=0.07$ for EAA, $p=$ 0.56 for NEAA, and $p=0.17$ for TAA). The arterial plasma BCAA, EAA, NEAA, and TAA concentrations during both HEGC and HEAC periods are depicted in Fig. 3. All plasma amino acid groups showed significant decreases during HEGC and subsequently increased during HEAC (Table 2).

\section{Glucose and leucine disposal rates}

The mean GDR derived by HEGC was $5.1 \pm 2.1 \mathrm{mg} / \mathrm{kg} /$ min for MHD patients and $6.3 \pm 3.9 \mathrm{mg} / \mathrm{kg} / \mathrm{min}$ for control subjects $(p=0.38$; Table 3$)$. Similarly, the mean GDR obtained from HEAC was also slightly higher in control subjects but the difference did not reach statistical significance $(6.7 \pm 2.1 \mathrm{mg} / \mathrm{kg} / \mathrm{min}$ for MHD vs $7.9 \pm$ $4.5 \mathrm{mg} / \mathrm{kg} / \mathrm{min}$ for control, $p=0.35$ ) (Table 3 ). The administration of amino acid infusion resulted in significant increases in GDR both for MHD patients and control subjects. $(P<0.001)$ (Fig. 4$)$.

The mean LDR level was statistically significantly higher in control subjects compared MHD patients $[(0.09 \pm 0.03 \mathrm{mg} / \mathrm{kg} / \mathrm{min}$ for MHD vs $0.11 \pm 0.05 \mathrm{mg} / \mathrm{kg} /$ min for control, $P=0.009$ )] (Table 3 ).

Correlation coefficients of the GDR derived by HEGC and LDR are depicted in Fig. 5. There was a significant positive correlation between GDR and LDR levels for the whole study population $(r=0.65, p<0.001$, Fig. 5a). Correlation analysis for the two individual groups revealed that GDR derived by HEGC and LDR correlated well in the control patients $(r=0.79, p<0.001$, Fig. 5c), whereas correlation was slightly attenuated in MHD patients $(r=0.58, p<0.001$, Fig. $5 b)$.

\section{Correlation analysis between leucine disposal rate derived by HEAC and protein turnover kinetics}

The mean \pm SD whole body (WB) protein synthesis and breakdown were $4.8 \pm 1.3,3.1 \pm 1.3 \mathrm{mg} / \mathrm{kg}$. fat free mass/ min for MHD patients, $4.7 \pm 0.9,2.7 \pm 0.6 \mathrm{mg} / \mathrm{kg}$.fat free mass/min for control patients. Although WB protein breakdown rate was numerically higher in MHD patients, the difference was not statistically significant $(p=0.29)$. There was no statistically significant difference for WB protein synthesis $(p=0.74)$. The median (IQR) WB protein net balance rates were $1.5(1.3,1.9) \mathrm{mg} / \mathrm{kg}$.fat free $\mathrm{mass} / \mathrm{min}$ for MHD and $1.9(1.4,2.1) \mathrm{mg} / \mathrm{kg}$. fat free mass/min for control patients $(p=0.08)$. There was a near significant positive correlation between LDR and WB protein synthesis $(r=0.25 ; p=0.08)$, and significant positive correlation with WB protein net balance $(r=0.85 ; p<$ 0.001 ) in the overall study population (Fig. 6). Positive 


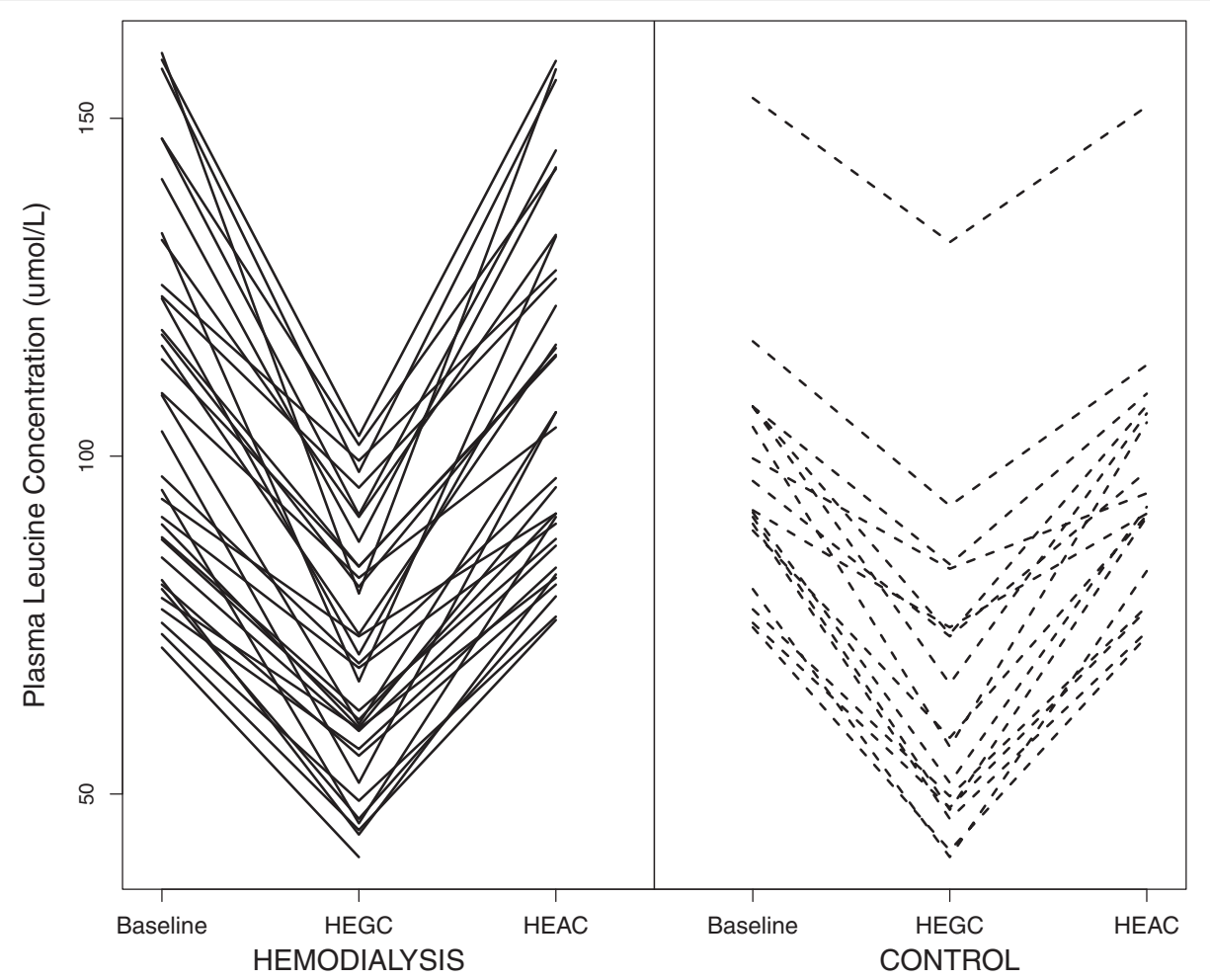

Fig. 2 Plasma Leucine Concentrations throughout the Clamp Study: Plasma leucine concentration was measured in the basal state and every ten minutes throughout the HEGC and HEAC studies. Leucine concentrations significantly decreased $(p<0.001)$ during the HEGC and significantly increased and maintained at the baseline level during HEAC ( $p=0.95$ for MHD, $p=0.73$ for control subjects)

correlations for WB protein synthesis remained significant in control group whereas attenuated in MHD patients $[r=0.10 ; p=0.59$ for MHD, $r=0.66 ; p=0.005$ for controls]. Both correlations were significant for WB protein net balance in subgroups analysis $[r=0.79$; $p<0.001$ for MHD, $r=0.94 ; p<0.001$ for control subjects]. There was a statistically significant negative correlation between LDR and WB protein breakdown $(r=-0.38$, $p=0.01)$. In subgroup analysis, significant negative correlation remained for MHD patients $(r=-0.41, p=0.02)$, whereas, no significant correlation observed in control subjects $(r=-0.23, p=0.38)$.

\section{Sensitivity analysis}

We examined the primary outcomes with exclusion of 8 patients in MHD group who had DM. The results indicated that GDR derived by HEGC levels were slightly lower in MHD patients compared to controls $(5.5 \pm 2.1 \mathrm{mg} / \mathrm{kg} / \mathrm{min}$ for MHD vs $6.3 \pm 3.9 \mathrm{mg} / \mathrm{kg} / \mathrm{min}$ for control, $p=0.59$ ). Similarly, no significant difference was observed for GDR derived by HEAC $(6.8 \pm 2.1 \mathrm{mg} /$ $\mathrm{kg} / \mathrm{min}$ for MHD vs $7.9 \pm 4.5 \mathrm{mg} / \mathrm{kg} / \mathrm{min}$ for control, $p$ $=0.43$ ). The mean LDR values were $0.09 \pm 0.03 \mathrm{mg} / \mathrm{kg} /$ min for MHD and $0.11 \pm 0.04 \mathrm{mg} / \mathrm{kg} / \mathrm{min}$ for controls $(p=0.03)$. The correlation analyses were similar to overall results. Specifically, there was a significant positive correlation between GDR and LDR levels in the whole study population $(r=0.64, p<0.001)$, controls $(r=0.78$, $p=0.001)$ and slightly attenuated in MHD patients $(r=$ $0.52, p=0.006$ ). The correlation analysis between LDR derived by HEAC and WB protein turnover kinetics revealed similar results. There was a positive correlation between LDR derived by HEAC and WB protein synthesis $(r=0.22, p=0.14)$, significant negative correlation with WB protein breakdown $(r=-0.43, p=0.005)$ and significant positive correlation with WB net protein balance $(r=0.84, p<0.001)$ in all study population. Positive correlation with $\mathrm{WB}$ protein synthesis remained significant $(r=0.66, p=0.004)$ for controls and attenuated for MHD patients $(r=0.04, p=0.84)$. The negative correlation with WB protein breakdown remained significant in MHD patients $(r=-0.56, p=0.004)$ whereas no significant correlation found for the control subjects $(r=-0.23, p=0.37)$. The significant positive correlations with WB protein net balance remained significant in subgroup analysis $[r=0.77, p<0.001$, for MHD patients and $r=0.94 p<0.001$ for control subjects].

\section{Discussion}

Insulin is an important key regulatory hormone with multiple effects on glucose, protein, and lipid metabolism. Previous studies have suggested a significant attenuation 

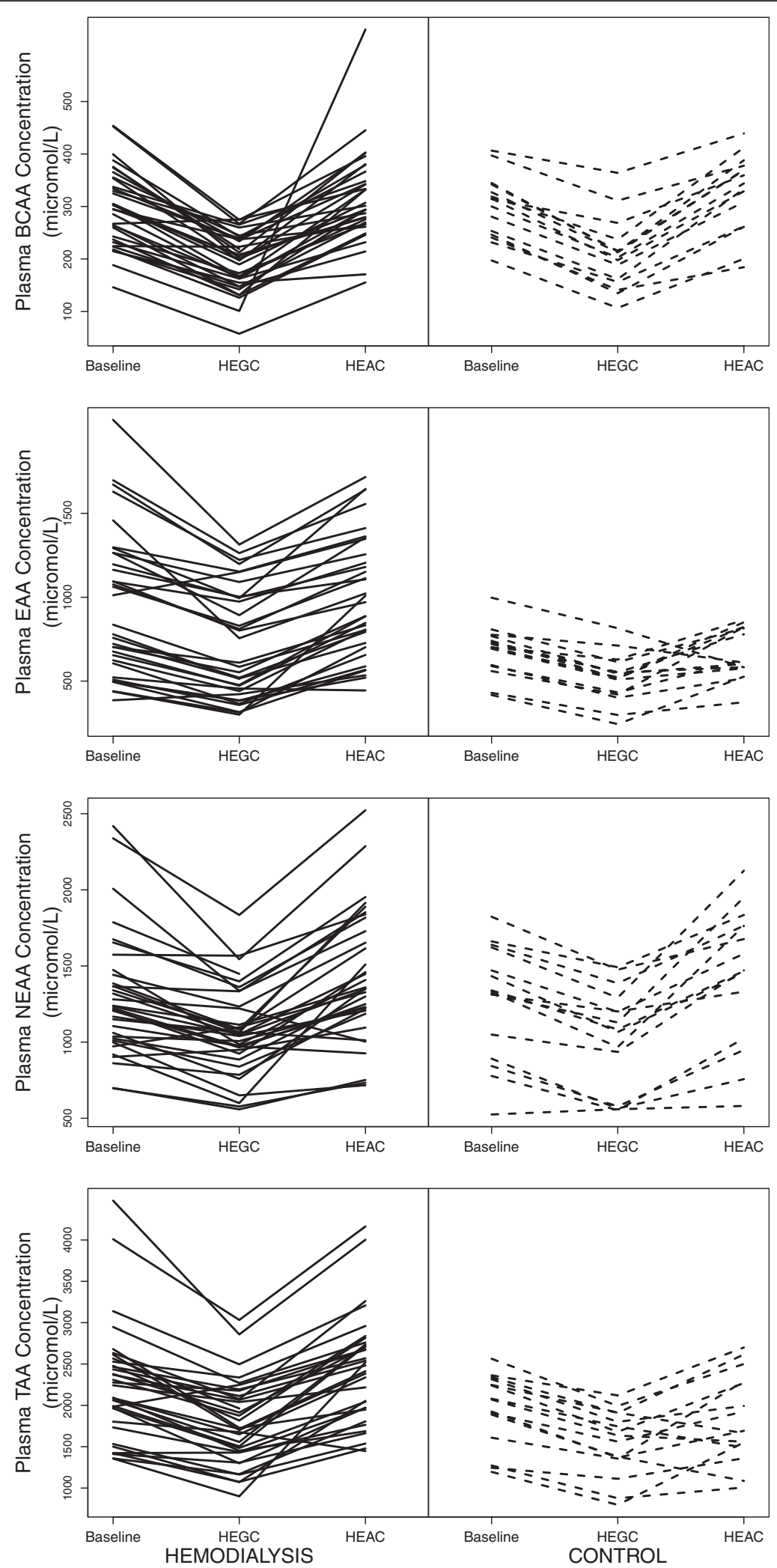

Fig. 3 (See legend on next page.) 
(See figure on previous page.)

Fig. 3 Plasma BCAA, EAA, NEAA, and TAA Levels during the HEGC and HEAC: Within group testing revealed achievement of statistical significance for change in levels between the three time points in all groups (Table 2). Testing between groups at baseline revealed no statistically significant differences ( $p=0.64$ for BCAA, $p=0.07$ for EAA, $p=0.56$ for NEAA, $p=0.17$ for TAA). BCAA; branched chain amino acid, EAA; essential amino acid, NEAA; nonessential amino acid; TAA, total amino acid

in insulin sensitivity on carbohydrate metabolism in ESRD patients on MHD. In the present study, we aimed to examine insulin sensitivity in terms of protein metabolism using a precise measure for amino acid utilization. Our data suggested that there is a statistically significant difference in amino acid utilization between MHD patients and matched controls. Interestingly, we were not able to confirm the previously published data, which reported a statistically significant difference in carbohydrate metabolism between MHD patients and controls. The correlation analyses with whole body protein synthesis, breakdown and net balance confirmed that we were able to accurately measure amino acid disposal rates both in MHD patients and controls without kidney disease. Presence or absence of diabetes did not influence the results indicating that this approach can be used in multiple settings. Finally, we observed that GDR and LDR correlated well in the control subjects, but less in MHD patients suggesting that insulin signaling might be coordinated differently at the protein level as compared to carbohydrate metabolism in ESRD patients on MHD.

The primary aim of our study was to develop and test the dual clamp procedure in MHD patients and individuals without kidney disease. Several technical aspects of our study indicate that this methodology can be applied in multiple settings. First, euglycemia and euaminoacidemia (based on plasma glucose and leucine concentrations) were achieved successfully at both time points in both groups. Second, we were able to achieve targeted insulin levels during glucose and amino acid clamps in both groups. The potential bias that could arise due to lack of agreement in these values is obvious and similarity is necessary in completing the clamp study. Achievement of target insulin concentrations will also suppress leucine production from protein degradation, which is critical for the reliability of the LDR. Third, leucine was chosen as the amino acid to be measured based on results from our previous study demonstrating correlation of leucine levels with differences seen in insulin resistance [9]. Measurement of leucine was achievable at the bedside using rapid HPLC, thus allowing for adjustment of the amino acid solution appropriately during the study period. Fourth, we were able to demonstrate a range of LDR in both MHD patients and individuals without kidney disease suggesting biological plausibility. Furthermore, the significant correlation of LDR with whole body protein kinetics particularly with protein synthesis, suggests that the LDR is reliable, relatively easy to perform at bedside and physiologically relevant measure of protein metabolism without further examination of protein turnover kinetics, the commonly used methodology for this purpose.

There are also several observations during the study that require further explanation. Our results showed that GDR values significantly increased during HEAC period as compared to HEGC period. Picchini et al. previously demonstrated that glucose uptake does increase when the HEGC is extended beyond the customary 2-h study period and the time difference between the HEGC and the HEAC can be at times close to $4 \mathrm{~h}$ suggesting a possible explanation for the observed increase between clamp periods [17]. There are also studies that show that leucine infusion per se can increase glucose utilization in healthy individuals $[18,19]$. Overall, the underlying cause of this increase in GDR might be due to either factors combined or one alone. The fact that both patient groups increased their GDR equally suggests that this observation is unlikely to be related to or worsened by advanced kidney disease. One could suggest that the separation of the GDR obtained during the HEGC from the LDR obtained during the HEAC introduces bias as these time points represent different states of insulin sensitivity. From an analytical perspective, we chose to use GDR derived from HEGC for analysis instead of

Table 2 Arterial concentrations of branched chain, essential, nonessential, and total amino acids during hyperinsulinemic states ${ }^{a}$

\begin{tabular}{|c|c|c|c|c|c|c|c|c|}
\hline & Hemodialysis & & & & Control & & & \\
\hline Amino Acids & Baseline & HEGC & HEAC & $P$ & Baseline & HEGC & HEAC & $P$ \\
\hline BCAA & $295(240,346)$ & $199(157,237)$ & $298(267,347)$ & $<0.001$ & $314(253,342)$ & $203(159,226)$ & $344(298,378)$ & $<0.001$ \\
\hline EAA & $779(615,1230)$ & $597(445,998)$ & $929(737,1243)$ & $<0.001$ & $701(590,769)$ & $522(426,583)$ & $622(582,822)$ & $<0.001$ \\
\hline NEAA & $1234(1030,1458)$ & $1049(930,1230)$ & $1355(1209,1710)$ & $<0.001$ & $1340(1049,1622)$ & $1083(757,1246)$ & $1485(1331,1764)$ & $<0.001$ \\
\hline TAA & $2243(1883,2503)$ & $1721(1140,2104)$ & $2448(1969,2733)$ & $<0.001$ & $2070(1889,2316)$ & $1635(1362,1854)$ & $1926(1551,2293)$ & $<0.001$ \\
\hline
\end{tabular}

$B C A A$ branched chain amino acid, EAA essential amino acid, HEAC hyperinsulinemic-euglycemic-euaminoacidemic clamp, HEGC hyperinsulinemic-euglycemic clamp, NEAA nonessential amino acid, TAA total amino acid

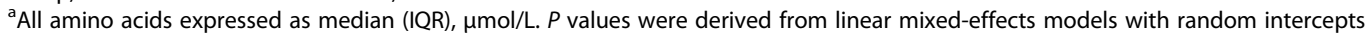


Table 3 Measures of insulin sensitivity by dual clamp study ${ }^{a}$

\begin{tabular}{llll}
\hline & $\begin{array}{l}\text { Hemodialysis } \\
(n=35)\end{array}$ & $\begin{array}{l}\text { Control } \\
(n=17)\end{array}$ & $P$ \\
\hline Carbohydrate Metabolism & & & \\
HEGC GDR, mg/kg/min & $5.1 \pm 2.1$ & $6.3 \pm 3.9$ & 0.38 \\
HEAC GDR, mg/kg/min & $6.7 \pm 2.1$ & $7.9 \pm 4.5$ & 0.35 \\
$\begin{array}{llll}\text { Protein Metabolism } \\
\quad \text { Leucine Disposal Rate, mg/kg/min }\end{array}$ & $0.09 \pm 0.03$ & $0.11 \pm 0.05$ & 0.009
\end{tabular}

GDR glucose disposal rate, HEAC hyperinsulinemic-euglycemiceuaminoacidemic clamp, $H E G C$ hyperinsulinemic-euglycemic clamp

${ }^{\text {a }}$ Results expressed as median \pm SD
GDR obtained from HEAC, since GDR at HEGC represents a real fasting state of amino acid feeding.

The current study did not reveal a significant difference between the GDR of the controls and the MHD subjects, somewhat contrary to published data. It is conceivable that the current lack of significance in absolute difference between the two groups is due only to the sample size of this study although we are reporting the largest study of its kind in MHD patients. It is also possible that this difference is the result of the individuals selected for study. In looking at the MHD subjects studied, one can see that this cohort of individuals is relatively healthy compared to the general population currently receiving renal replacement therapy as exemplified by serum albumin concentrations comparable to

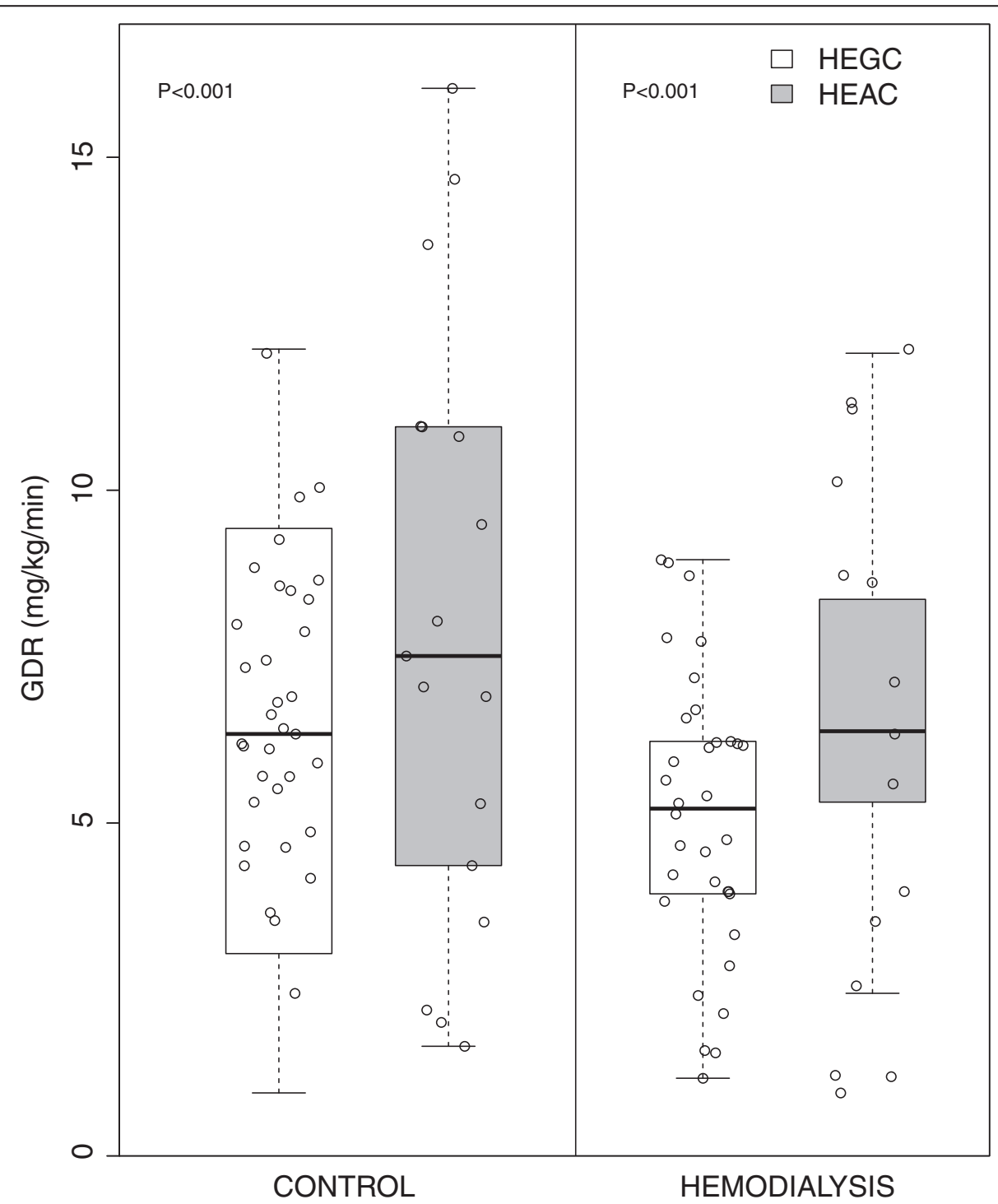

Fig. 4 Glucose disposal rate in each group at HEGC and HEAC: Difference in GDR between the two time points in both the MHD subjects and controls achieved statistical significance $(P<0.001$ in each) 

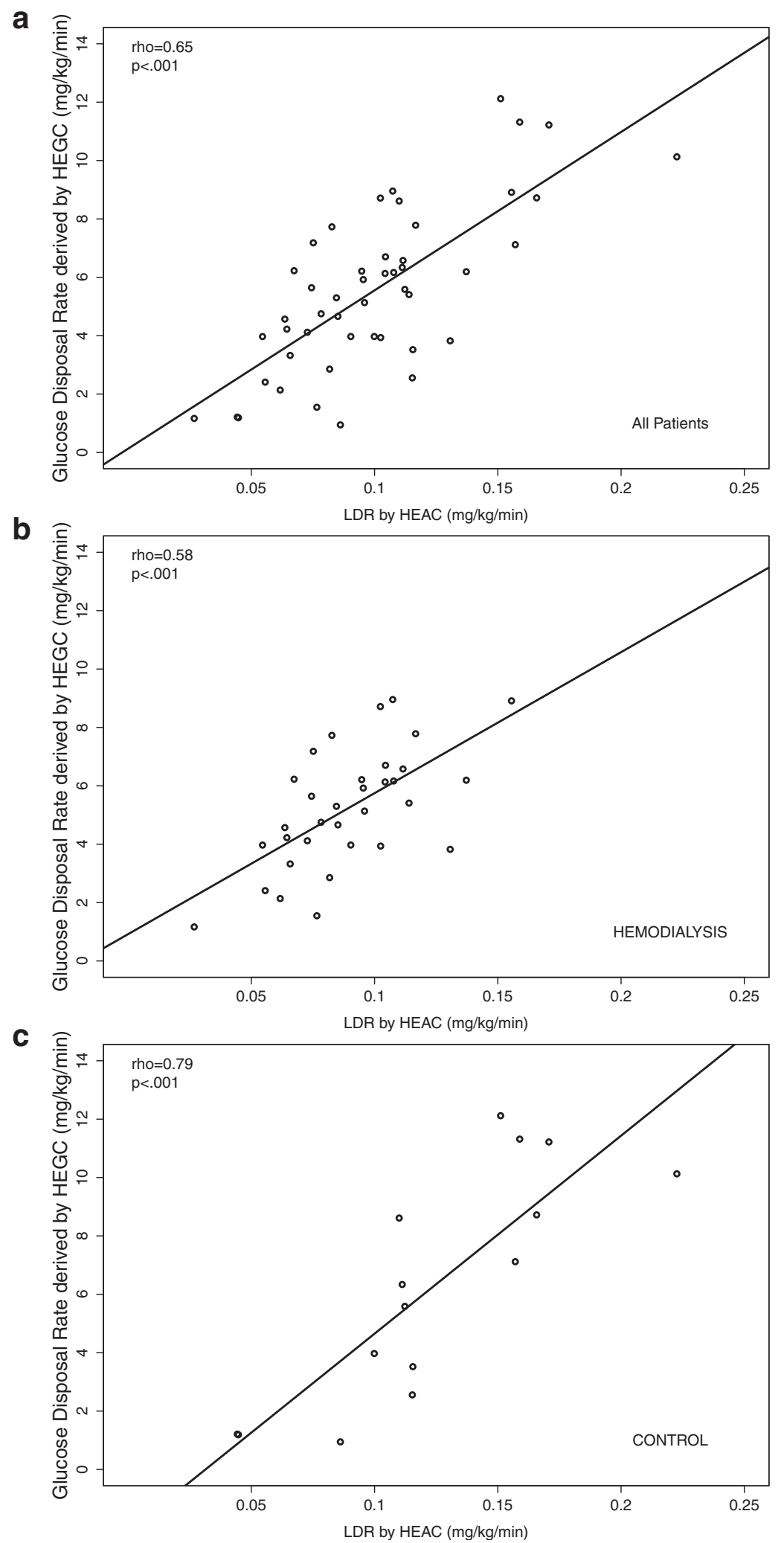

Fig. 5 Spearman Correlation Analysis of Glucose Disposal and Leucine Disposal Rates: a All patients, b Hemodialysis patients, c Control Patients: HEGC; hyperinsulinemic euglycemic clamp 


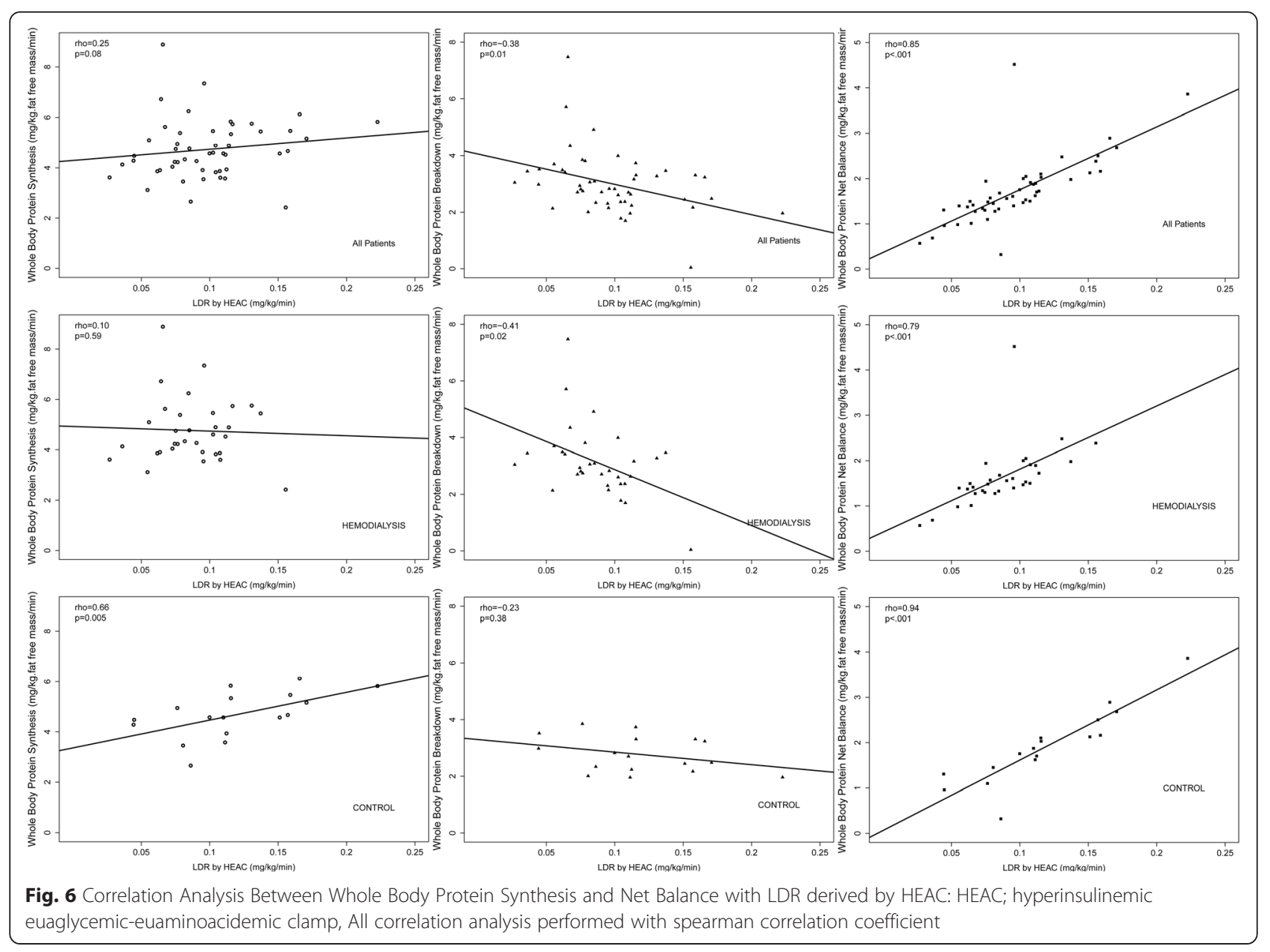

the controls studied. This is also one of the few studies where MHD patients are studied with appropriate controls, especially ones that have similar demographic and nutritional characteristics such as age, race, gender and body mass index. This may suggest that the difference between the two appropriately matched populations is not quite as large for GDR as previously suggested and is consistent with a recently published study in CKD patients not yet on maintenance dialysis [20]. Implementation of suitable control groups in future studies would provide valuable insight to this question.

Interestingly enough, we were able to detect a statistically significant difference between MHD patients and controls for LDR. The clinical and research implications of this observation are several folds, especially in the light of the aforementioned lack of difference in GDR. First and foremost important implication is that a significant number of MHD patients might be missing a potential opportunity for improvement if their management of insulin metabolism is solely based on markers of glucose metabolism such as random glucose concentrations or $\mathrm{Hb}_{\mathrm{Alc}}$. Indeed, it is generally believed that diabetes is somewhat resolved once MHD is commenced and antidiabetic agents are sparingly used in ESRD patients. These data further suggest that the choice of anti-diabetic agents in ESRD should be preferentially ones that improve insulin sensitivity rather than simply lowering blood glucose concentrations. Finally, it is imperative that further research examining anti-diabetic strategies in MHD patients must incorporate markers of protein metabolism in addition to other outcomes.

An intriguing finding in this study was that the correlation between GDR and LDR was relatively strong for the overall cohort; however, when compared within groups, the correlation coefficient was attenuated in MHD patients compared to controls (Fig. $5 \mathrm{~b}$ and c). This observation suggests that the metabolic response of carbohydrates and amino acids to insulin is coordinated differentially in the setting of advanced kidney disease, which is in line with the data showing the discrepancy between GDR and LDR when comparing MHD patients and matched controls. In animal studies, Mitch and colleagues have shown that kidney disease leads to decrease insulin receptor substrate 1 (IRS-1) with a compensatory increase 
in IRS-2 [21] and reduced Akt phosphorylation. This finding might support the discrepancy in insulin sensitivity on carbohydrate and protein metabolism in our study, although further examination at the muscle tissue level would provide the more insight to this novel in vivo observation in the setting of advanced kidney disease.

There are several strengths in this study. This is the first study to develop and test a physiologically relevant method for assessing insulin sensitivity for protein metabolism in humans. It is one of the largest cohorts using a dual-clamp method in MHD patients and individuals without kidney disease. The inclusion of a control population that represents the clinical and demographic characteristics of the contemporary ESRD patient population is a unique strength. The inclusion of metabolicstudies with labeled isotopes further strengthens the study and the validity of the results obtained. There are also several limitations in this study. Predominance of male gender and African-American race limits the generalizability of the study. It is possible that statistical significance would be achieved when comparing GDR between groups with a larger sample size; however, the current findings may be true in that the previously perceived difference between the two groups may not be as large as once thought as recently has been shown in two separate studies in CKD patients. The methodology is complex and cannot be readily applied in every setting. Nevertheless, it is arguably the most appropriate research approach for measuring insulin action in the stimulated setting. Further studies exploring more practical measures that relate to amino acid disposal are necessary to further advance knowledge in this area. Finally, LDR does not necessarily provide direct evidence of the effects of insulin on different components of protein metabolism, namely protein synthesis and breakdown. Additional studies incorporating stable isotope technique at different settings of amino acid concentrations would shed further light into those aspects of protein homeostasis, both in healthy controls and chronic disease settings such as ESRD.

\section{Conclusion}

LDR derived by HEAC technique offers a reliable and physiological method to quantify insulin sensitivity on protein turnover in MHD patients and individuals without kidney disease. There is a statistically significant difference between MHD patients and controls for LDR, but not for GDR. The additional data showing attenuated correlation between GDR and LDR in response to insulin suggest that the mechanisms contributing to the resistance in protein metabolism extend beyond carbohydrate metabolism in the MHD patients. These findings require further investigation for understanding the effects of insulin signaling on protein metabolism in MHD patients.

\section{Abbreviations}

BCAA, branched chain amino acids; DEXA, dual-energy x-ray absorptiometry; DM, diabetes mellitus; EAA, essential amino acids; ESRD, end stage renal disease; GCRC, general clinical research center; GDR, glucose disposal rate; HEAC, hyperinsulinemic-euglycemic-euaminoacidemic clamp; HEGC, hyperinsulinemic-euglycemic clamp; HOMA-IR, homeostasis model assessment of insulin resistance; HPLC, high-performance liquid chromatography; LBM, lean body mass; LDR, leucine disposal rate; MHD, maintenance hemodialysis; NEAA, nonessential amino acids; PEW, protein energy wasting; TAA, total amino acids; VUMC, Vanderbilt University Medical Center.

\section{Acknowledgements}

This study was supported in part by the U.S. Department of Veterans Affairs under Award Number 1101CX000414, Clinical Translational Science Award UL1TR000445 from the National Center for Advancing Translational Sciences, Vanderbilt Diabetes Research and Training Center Grant P30 DK020593, Vanderbilt O'Brien Mouse Kidney Center Grant P30 DK079341, T32 DK007569 and K24 DK62849 from the National Institute of Diabetes and Digestive and Kidney Diseases, Vanderbilt Center in Molecular Toxicology Grant P30 ES000267 from the National Institute of Environmental Health Sciences and Vanderbilt Center for Kidney Disease. Serpil M. Deger is currently a fellow of the American Heart Association.

\section{Availability of data and materials}

The unidentified data from this study is available through corresponding author for any interested party with appropriate rationale.

\section{Authors' contributions}

BGD; involved in collecting the data, performing the data analysis, interpretation the results and writing the manuscript, SMD; involved in collecting the data, performing the data analysis, interpretation the results and writing the manuscript, GC; involved in performing the final data analysis, $A B$; involved in performing the final data analysis, FS; performed amino acid measurements, $C B$; involved in conducting the study, collecting the data, JTK; performed bed-side plasma glucose measurements, SD; involved in collecting data, CDE; involved in the collecting the data and writing the manuscript, TAl; involved in designing and conducting study, collecting data, interpretation of final results and writing manuscript. All authors approved of the final manuscript.

\section{Competing interests}

The authors declare that they have no competing interests.

\section{Consent to publish}

Not applicable.

\section{Author details}

${ }^{1}$ Division of Nephrology, Vanderbilt University Medical Center, 1161 21St Ave. South \& Garland, S-3223 MCN, Nashville, TN 37232-2372, USA. ${ }^{2}$ CSRD\&D, Veterans Administration Tennessee Valley Healthcare System, Nashville, TN, USA. ${ }^{3}$ Vanderbilt Center for Kidney Disease, Nashville, TN, USA. ${ }^{4}$ Department of Biostatistics, Vanderbilt University Medical Center, Nashville, TN, USA.

${ }^{5}$ University of Rochester School of Medicine and Dentistry, Rochester, NY, USA.

Received: 14 December 2015 Accepted: 27 May 2016

Published online: 03 June 2016

\section{References}

1. Ikizler TA, Wingard RL, Harvell J, Shyr Y, Hakim RM. Association of morbidity with markers of nutrition and inflammation in chronic hemodialysis patients: a prospective study. Kidney Int. 1999;55(5):1945-51.

2. Ikizler TA, Hakim RM. Nutrition in end-stage renal disease. Kidney Int. 1996;50(2):343-57.

3. Fouque D, Kalantar-Zadeh K, Kopple J, Cano N, Chauveau P, Cuppari L, Franch $H$, Guarnieri G, Ikizler TA, Kaysen $G$ et al. A proposed nomenclature and diagnostic criteria for protein-energy wasting in acute and chronic kidney disease. Kidney Int. 2008;73(4):391-8.

4. Fung F, Sherrard DJ, Gillen DL, Wong C, Kestenbaum B, Seliger S, Ball A, Stehman-Breen C. Increased risk for cardiovascular mortality among 
malnourished end-stage renal disease patients. Am J Kidney Dis. 2002;40(2):307-14.

5. Lacson Jr E, Wang W, Lazarus JM, Hakim RM. Hemodialysis facility-based quality-of-care indicators and facility-specific patient outcomes. Am J Kidney Dis. 2009;54(3):490-7.

6. Jadeja YP, Kher V. Protein energy wasting in chronic kidney disease: an update with focus on nutritional interventions to improve outcomes. Indian J Endocrinol Metab. 2012;16(2):246-51.

7. Lacson Jr E, Wang W, Hakim RM, Teng M, Lazarus JM. Associates of mortality and hospitalization in hemodialysis: potentially actionable laboratory variables and vascular access. Am J Kidney Dis. 2009;53(1):79-90.

8. Pupim LB, Heimburger O, Qureshi AR, Ikizler TA, Stenvinkel P. Accelerated lean body mass loss in incident chronic dialysis patients with diabetes mellitus. Kidney Int. 2005;68(5):2368-74.

9. Deger SM, Sundell MB, Siew ED, Egbert P, Ellis CD, Sha F, Ikizler TA, Hung AM. Insulin resistance and protein metabolism in chronic hemodialysis patients. J Ren Nutr. 2013;23(3):e59-66.

10. Flakoll PJ, Carlson M, Cherrington AC. Physiological action of insulin. In: Leroith DTS, Olefsky J, editors. Diabetes mellitus: a fundamental and clinical text. 2nd ed. Philadelpia: Williams \& Wilkins; 2000. p. 148-61.

11. McGuire EA, Helderman JH, Tobin JD, Andres R, Berman M. Effects of arterial versus venous sampling on analysis of glucose kinetics in man. J Appl Physiol. 1976;41(4):565-73.

12. Smith $\mathrm{D}$, DeFronzo RA. Insulin resistance in uremia mediated by postbinding defects. Kidney Int. 1982;22(1):54-62.

13. Heinrikson RL, Meredith SC. Amino acid analysis by reverse-phase high-performance liquid chromatography: precolumn derivatization with phenylisothiocyanate. Anal Biochem. 1984;136(1):65-74.

14. Wolfe RR. Radioactive and stable isotope tracers in biomedicine: principles and practice of kinetic analysis. New York: Wiley-Liss; 1992. p. 283-316.

15. Allsop JR, Wolfe RR, Burke JF. Tracer priming the bicarbonate pool. J Appl Physiol. 1978:45:137-9.

16. Garlick PJ, McNurlan MA, McHardy KC, Calder AG, Milne E, Fearns LM, Broom $J$. Rates of nutrient utilization in man measured by combined respiratory gas analysis and stable isotopic labeling: effect of food intake. Hum Nutr Clin Nutr. 1987;41:177-91.

17. Picchini U, De Gaetano A, Panunzi S, Ditlevsen S, Mingrone G. A mathematical model of the euglycemic hyperinsulinemic clamp. Theor Biol Med Model. 2005;2:44.

18. van Loon LJ, Kruijshoop M, Menheere PP, Wagenmakers AJ, Saris WH, Keizer HA. Amino acid ingestion strongly enhances insulin secretion in patients with long-term type 2 diabetes. Diabetes Care. 2003;26(3):625-30.

19. Tappy L, Acheson K, Normand S, Pachiaudi C, Jequier E, Riou JP. Effects of glucose and amino acid infusion on glucose turnover in insulin-resistant obese and type II diabetic patients. Metabolism. 1994;43(4):428-34.

20. de Boer IH, Zelnick L, Afkarian M, Ayers E, Curtin L, Himmelfarb J, Ikizler TA Kahn SE, Kestenbaum B, Utzschneider K. Impaired Glucose and Insulin Homeostasis in Moderate-Severe CKD. J Am Soc Nephrol. 2016. [Epub ahead of print].

21. Bailey JL, Zheng B, Hu Z, Price SR, Mitch WE. Chronic kidney disease causes defects in signaling through the insulin receptor substrate/ phosphatidylinositol 3-kinase/Akt pathway: implications for muscle atrophy. J Am Soc Nephrol. 2006;17(5):1388-94.

\section{Submit your next manuscript to BioMed Central and we will help you at every step:}

- We accept pre-submission inquiries

- Our selector tool helps you to find the most relevant journal

- We provide round the clock customer support

- Convenient online submission

- Thorough peer review

- Inclusion in PubMed and all major indexing services

- Maximum visibility for your research

Submit your manuscript at www.biomedcentral.com/submit
Biomed Central 